\title{
On The Finite Element Modeling Of Turbo Machinery Rotors In Rotor Dynamic Analysis
}

\author{
Mohammad hadi Jalali \\ Faculty of Engineering and Applied \\ Science \\ Memorial University \\ St. John's, Canada
}

\author{
Nima Nouri \\ Isfahan University of Technology \\ Department of Mechanical \\ Engineering \\ Isfahan, Iran
}

\author{
Saeed Ziaei-Rad \\ Isfahan University of Technology \\ Department of Mechanical \\ Engineering \\ Isfahan, Iran
}

\begin{abstract}
In this study, a program based on finite element method is developed for rotor dynamic analysis of gas turbine rotors. In the FE model of the rotors, various minor and major parts of the rotor are modeled using the cylindrical and tapered Timoshenko beam elements and the lateral vibration behavior of the rotor is evaluated. In the paper, the lateral vibration behavior of a certain gas turbine rotor is analyzed using the developed finite element program and coupled lateral-torsional vibration behavior of the rotor is analyzed using 3D finite element model. A good agreement exists between the results obtained from two FE models. Two design models are used for the rotor one of which has 2 bearings and the other one has 4 bearings with specific locations. The effects of the number of the bearings on the critical speeds, operational deflection shapes and unbalance response of the rotor is investigated. It is found that the number of the bearings has significant effect on the first critical speed but slight effect on the second and third critical speeds. It is demonstrated that the number of the bearings can be used as one of the system design parameters.
\end{abstract}

Keywords; Timoshenko beam elements, Dynamic analysis, Campbell diagram, Unbalance response, Operational deflection shape

\section{INTRODUCTION}

Rotor dynamics is a branch of systems dynamics dealing with mechanical systems in which at least one part, usually defined as rotor, rotates with significant angular momentum [14]. It is vital to consider the dynamics of the rotating machines in the design stage to avoid catastrophic failures that may occur because of resonance condition in their operation. Dynamic analysis of rotating machines and turbo machinery rotors has been performed by many researchers and finite element method has been of interest of many researchers recently as a numerically efficient method to analyze the dynamics of rotating machines and mechanical structures [5-10].

Chiang et al. [11] developed finite element models to investigate the dynamic characteristics of single- and dualrotor-bearing turbomachinery systems. The models were analyzed to predict the natural frequencies, produce critical speed maps, and estimate the bearing stiffness. They demonstrated that the speed ratio of the high speed to lowspeed shaft in dual-rotors could be used as one of the dual-rotor system design parameters. Jeon et al. [12] performed a full rotor dynamic analysis for a high thrust liquid rocket engine fuel turbo pump using finite element method. They found out that the rear bearing stiffness was the most important parameter for the critical speed and instability, because the first vibration mode of the rotor was turbine side shaft bending mode. Jeon et al. [13] used 1D and three-dimensional finite element methods to perform critical speed analysis of a 30-ton thrust turbo pump while considering the casing structural flexibility. They also analyzed the effect of loads on the bearings on the dynamic behavior of the rotor. Jalali et al. [14, 15] predicted the dynamic behavior of a rotor-bearing system with a 1D finite element model, a 3D finite element model and experimental modal test. They obtained natural frequencies and mode shapes of the rotor at rest under free-free boundary condition using beam model, 3D model and modal test. Also, they performed a full rotor dynamic analysis for the rotor using both FE models. Brusa and Zolfini [16] investigated the dynamic behavior of the Galileo Galilei Ground (GGG) test facility through numerical and experimental analyses. They used one dimensional beam finite element model to model the system and They compared the results with experimental results. Creci et al. [17] performed a full rotor dynamic analysis for a $5-\mathrm{KN}$ thrust gas turbine using a 1D finite element model considering bearing stiffness and damping dynamics. They obtained mode shapes and operational deflection shapes of the rotor and they performed a transient analysis to simulate the transition of the system through resonance.

In this paper, a finite element model based on cylindrical and tapered Timoshenko beam elements, by considering the rotary inertia, gyroscopic effect and shear deformations, is used to study the dynamic behavior of a gas turbine rotor. The difference of this beam FE model with the models in the literature is that the various minor and major parts of the rotor are modeled with beam elements in this model, therefore dynamics of the rotor can be evaluated exactly. A 3D finite element model based on solid elements is also constructed in 
Ansys software to validate the beam FE results. A parameter study is carried out to examine the effects of the number of the bearings on the lateral vibration behavior of the rotor. The mode shapes, Campbell diagram, critical speeds, operational deflection shapes (ODS) and unbalance response of the rotor are obtained in both cases with 2 bearings and 4 bearings with specific locations to compare the dynamics of the designed rotors and to evaluate which design would be better. It is found that the number of the bearings can be a design parameter, because it influences the vibration behavior of the rotor significantly.

\section{THEORETICAL FORMULATION}

The rotor system can be divided into rigid disks, rotor segments, and linear bearing supports. The vector of the nodal displacements, i.e., of the generalized coordinates of a Timoshenko beam element used in this study is:

$$
q=\left[\begin{array}{llllllll}
x_{1} & y_{1} & \theta_{x 1} & \theta_{y 1} & x_{2} & y_{2} & \theta_{x 2} & \theta_{y 2}
\end{array}\right]
$$

Where $x_{1}, y_{1}, \theta_{x 1}$ and $\theta_{y 1}$ represent node 1 's displacements and rotations about the nodal axes and $x_{2}, y_{2}, \theta_{x 2}$ and $\theta_{y 2}$ represent node 2 's displacements and rotations about the nodal axes. The value of displacements through the elements can be obtained by shape functions and the nodal displacements from the following equation.

$$
\begin{aligned}
& \left\{\begin{array}{c}
x \\
\theta_{y}
\end{array}\right\}=\left[\begin{array}{llll}
N_{11} & N_{12} & N_{13} & N_{14} \\
N_{21} & N_{22} & N_{23} & N_{24}
\end{array}\right]\left\{\begin{array}{c}
x_{1} \\
\theta_{y 1} \\
x_{2} \\
\theta_{y 2}
\end{array}\right\} \\
& \left\{\begin{array}{c}
y \\
\theta_{x}
\end{array}\right\}=\left[\begin{array}{llll}
N_{11} & N_{12} & N_{13} & N_{14} \\
N_{21} & N_{22} & N_{23} & N_{24}
\end{array}\right]\left\{\begin{array}{c}
y_{1} \\
\theta_{x 1} \\
y_{2} \\
\theta_{x 2}
\end{array}\right\}
\end{aligned}
$$

Where $N_{i j}(i, j=1,2)$ are the shape functions of Timoshenko beam element which can be found in [18]. The motion equation of a complete rotor-bearing system that is axially symmetrical around its spin axis and rotates at a constant spin speed $\Omega$, is in the following general form:

$$
\mathbf{M} \ddot{\mathbf{q}}(\mathrm{t})+(\mathbf{G}) \dot{\mathbf{q}}(\mathrm{t})+(\mathbf{K}) \mathbf{q}(\mathrm{t})=\mathbf{f}(\mathrm{t})
$$

Where $\mathbf{q}(\mathrm{t})$ is a vector containing the generalized coordinates, referred to an inertial frame and the other matrices are the assembled matrices for the system. $\mathbf{M}$ is the symmetric mass matrix, $\mathbf{G}$ is the skew-symmetric gyroscopic matrix, $\mathbf{K}$ is the symmetric stiffness matrix, and $\mathbf{f}(\mathrm{t})$ is a time-dependent vector in which all forcing functions are listed. The gyroscopic matrix contains inertial and hence conservative terms that, in the case of rotor dynamics, are strictly linked with the gyroscopic moments acting on the rotating parts of the machine. When dealing with rotating systems, one of the forcing functions is usually that caused by the residual unbalance that, although small, cannot nevertheless be neglected. Unbalance forces are harmonic functions of time, with an amplitude proportional to $\Omega^{2}$ and a frequency equal to $\Omega$.

Most flexible rotors can be considered as beam-like structures. Under fairly wide assumptions, the lateral behavior of a beam can be considered as uncoupled from its axial and torsional behavior $[1,18]$. The same uncoupling is usually assumed in rotor dynamics, with the difference that no further uncoupling between bending in the principal planes is possible. When the flexural behavior can be uncoupled from the axial and torsional ones, Equation (3) holds for the first one.

In order to solve the eigenvalue problem of the Equation (3) (with $\mathbf{f}(\mathrm{t})=0$ ), the second-order homogeneous Equation (3) should be reduced into $2 \mathrm{n}$ first-order differential equations. A 2n-column vector $\mathrm{X}=\left\{\begin{array}{l}\dot{\boldsymbol{q}} \\ \boldsymbol{q}\end{array}\right\}$ is used so that Equation (3) with zero force can be expressed as:

$$
\left[\begin{array}{cc}
\mathbf{0} & \mathbf{M} \\
\mathbf{M} & \mathbf{G}
\end{array}\right]\left[\begin{array}{c}
\ddot{\mathbf{q}} \\
\dot{\mathbf{q}}
\end{array}\right]+\left[\begin{array}{cc}
-\mathbf{M} & \mathbf{0} \\
\mathbf{0} & \mathbf{K}
\end{array}\right]\left\{\begin{array}{l}
\dot{\mathbf{q}} \\
\mathbf{q}
\end{array}\right\}=\left\{\begin{array}{l}
\mathbf{0} \\
\mathbf{0}
\end{array}\right\}
$$

Equation (4) can be simplified into:

$$
\mathbf{A} \dot{\mathbf{X}}+\mathbf{B X}=\mathbf{0}
$$

By assuming $\mathbf{X}=\{\boldsymbol{\psi}\} e^{\lambda t}$, Equation (5) can be expressed as:

$$
\lambda \mathbf{A}+\mathbf{B}\{\boldsymbol{\psi}\}=\mathbf{0}
$$

The eigenvalues of the Equation (6) is $\lambda_{k}=\sigma_{k}+i \omega_{k}$ where $\sigma_{k}$ is the decay rate of the kth natural frequency and $\omega_{k}$ is the kth natural frequency. When the natural frequencies of the rotor at various rotor speeds are calculated, the Campbell diagram can be plotted. The natural frequencies of the rotor at various rotor speeds can be calculated by solving the eigenvalue problem Equation (6). In addition, the unbalance response of the rotor can be calculated by obtaining the solution of the Equation (7) which is derived when in Equation (3), $\mathbf{f}(\mathrm{t})$ is a harmonic function of time, with amplitude proportional to $\Omega^{2}$ and a frequency equal to $\Omega$ and by assuming the response to be $\mathbf{q}(\mathrm{t})=\mathbf{q}_{0} e^{i \omega t}$.

$$
\left(-\Omega^{2} \mathbf{M}+\mathrm{i} \Omega \mathbf{G}+\mathbf{K}\right) \mathbf{q}_{0}=\Omega^{2} \mathbf{f}_{r}
$$

\section{FINITE ELEMENT MODELS}

\section{A. Beam Finite element Model}

The studied rotor is a single spool gas turbine rotor and consists of two fan stages, six compressor stages and two turbine stages. The compressors and fans are made of aluminum alloy by the density of $4437 \mathrm{~kg} / \mathrm{m}^{3}$, Young modulus of $113.8 \mathrm{GPa}$ and the Poisson ratio of 0.342 . The material of the other parts of the rotor is assumed to be steel by the density 
of $7700 \mathrm{~kg} / \mathrm{m}^{3}$, Young modulus of $215 \mathrm{GPa}$ and the Poisson ratio of 0.3 . The total length of the shaft is $70 \mathrm{~cm}$. Figure 1 and Figure 2 show the finite element design model of the rotor with 2 and 4 bearings, respectively. In these Figures, disks D1 and D2 are the fan stages, D3-D8 are the compressor stages, D9 and D10 are the turbine stages and D11 is the turbine starter. The model of the rotor in both Figures is the same and only the number of the bearings is different. The model consists of 60 nodes and 78 Timoshenko beam elements. A mesh convergence analysis is performed to explain why this number of nodes and elements is used in the beam model, but the results are not presented in the paper for brevity. The parts with the same colors in Figs. 1-2 have the same materials. The effects of rotary inertia, gyroscopic moments and shear deformations are included in the formulations and the damping is neglected. The dimensions of the various parts of the rotor are exactly equal to those in the 3D FE model. Every node used in the system has 4 degrees of freedom. These include translations in the nodal directions and rotations about nodal axes. In order to consider the inertial properties of fans, compressors and turbines and turbine starter, concentrated masses are used at the place of each one. Table 1 shows the geometric properties of the discs. Inertial properties of the disks can be calculated from the dimensions given in Table 1 . Cylindrical Timoshenko beam elements are used to model the various parts of the shaft and the generator. It should be noted that, in order to model the rotor more accurately, some of the elements have equal nodes. It means that they are on top of each other with the same nodes. Tapered Timoshenko beam elements are used to model the minor parts such as the gaps between different stages of the fans, compressors and turbines. Springs are used to model the bearings at the place of bearings. Table 2 shows the stiffness coefficients of the bearings. The stiffness and damping cross-coupled terms for the bearings are considered null.

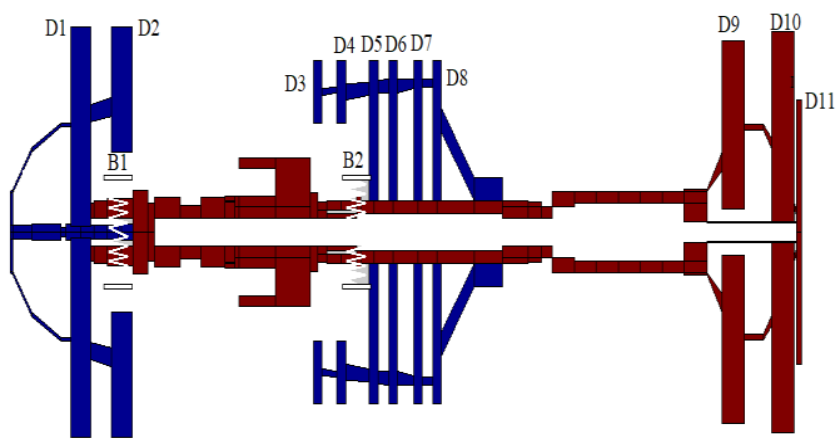

Figure 1. FE model of rotor with 2 bearings

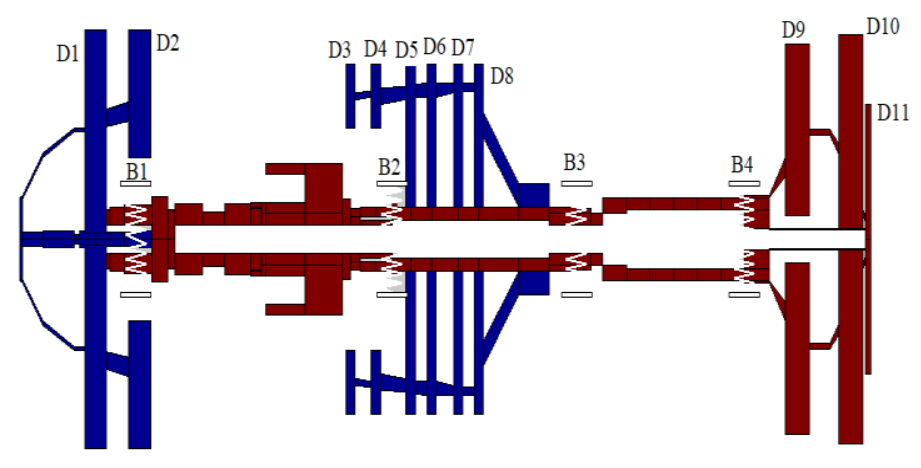

Figure 2. FE model of rotor with 4 bearings

TABLE 1. GEOMETRIC PROPERTIES OF DISCS

\begin{tabular}{|c|c|c|c|c|c|c|c|}
\hline Discs & D1 & D2 & $\begin{array}{c}\text { D3- } \\
\text { D4 }\end{array}$ & $\begin{array}{c}\text { D5- } \\
\text { D8 }\end{array}$ & D9 & D10 & D11 \\
\hline $\begin{array}{c}\text { Outer } \\
\text { diameter } \\
(\mathrm{mm})\end{array}$ & 262 & 262 & 219 & 219 & 244 & 257 & 169 \\
\hline $\begin{array}{c}\text { Inner } \\
\text { diameter } \\
(\mathrm{mm})\end{array}$ & 7.06 & 102 & 140 & 40 & 30.1 & 13.31 & 0 \\
\hline $\begin{array}{c}\text { Width } \\
(\mathrm{mm})\end{array}$ & 17.5 & 17.98 & 7.62 & 7.62 & 20 & 20 & 5 \\
\hline
\end{tabular}

TABLE 2. STIFFNESS COEFFICIENTS OF THE BEARINGS

\begin{tabular}{|c|c|}
\hline Bearing Number & Stiffness (N/m) \\
\hline B1 & $1.57 \mathrm{e}+07$ \\
\hline B2 & $1.77 \mathrm{e}+07$ \\
\hline B3 & $3.91 \mathrm{e}+06$ \\
\hline B4 & $7.04 \mathrm{e}+06$ \\
\hline
\end{tabular}

B. 3D Finite Element Model

The coupled lateral-torsional vibration analysis of the rotor is carried out using 3D FEM. The Ansys software is used to construct the 3D finite element model with 10 node tetrahedral solid elements. Figure 3 shows the 3D finite element model of the rotor. The model consists of 50809 nodes and 27982 solid elements. All the parts are considered elastic and the material and geometric properties of this rotor model are exactly equal to that of the beam finite element model. Spring elements in the two lateral directions are used at the place of the bearings to model the bearings for 2 and 4 bearing cases. 


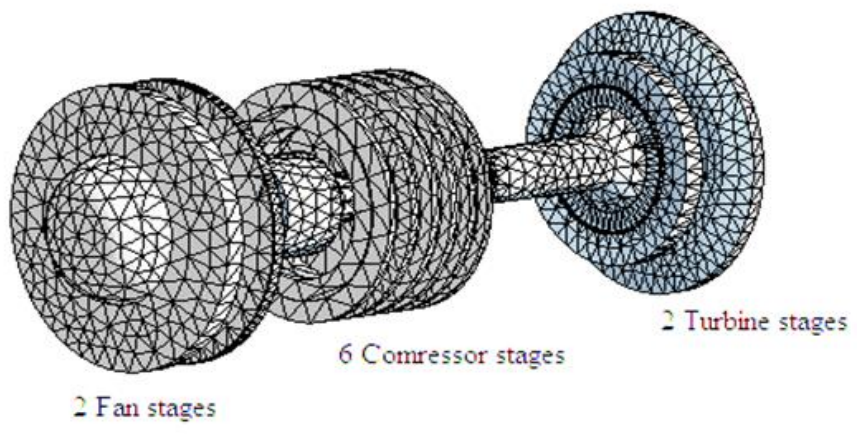

Figure 3. 3D Finite Element Model

\section{RESULTS}

\section{A. Dynamic Analysis of the Rotor with 2 Bearings}

In order to investigate the dynamic behavior of the rotor at operational speeds, critical speeds and the Campbell diagram are obtained using the beam FE model. The speed range considered is 0 to $36000 \mathrm{rpm}$. The Campbell diagram of the rotor obtained from beam FEM excluding the rigid body modes is illustrated in Figure 4. The three first bending critical speeds of the rotor corresponding to the forward whirling obtained from beam FE model are $2099.97 \mathrm{rpm}, 10479 \mathrm{rpm}$ and 15556 rpm, respectively. Also, the Campbell diagram obtained from $3 \mathrm{D}$ finite element model excluding the rigid body modes is shown in Figure 5. As can be seen, the gyroscopic softening/stiffening of some of the modes have minor error between two Figs. which is expected because of the difference in modeling methods of the inertial properties of the disks in two FE models.

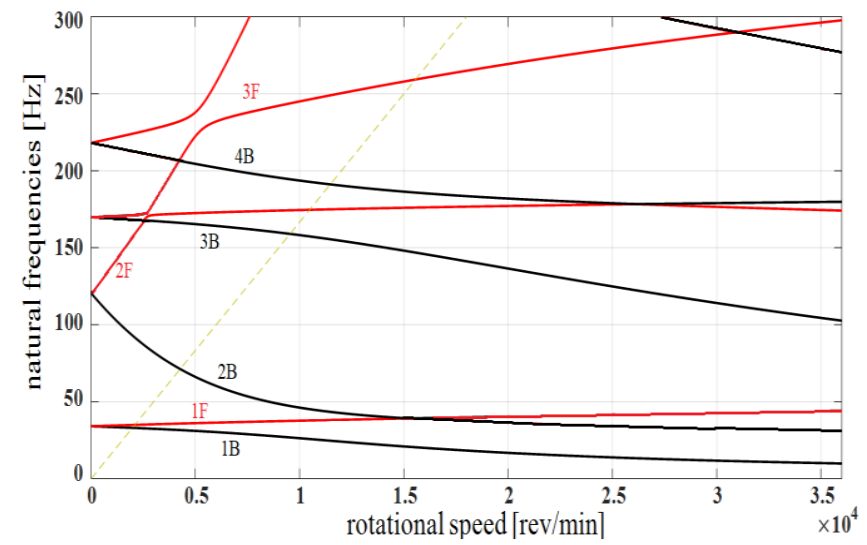

Figure 4. Campbell diagram of the rotor with 2 bearings (Beam FE model)

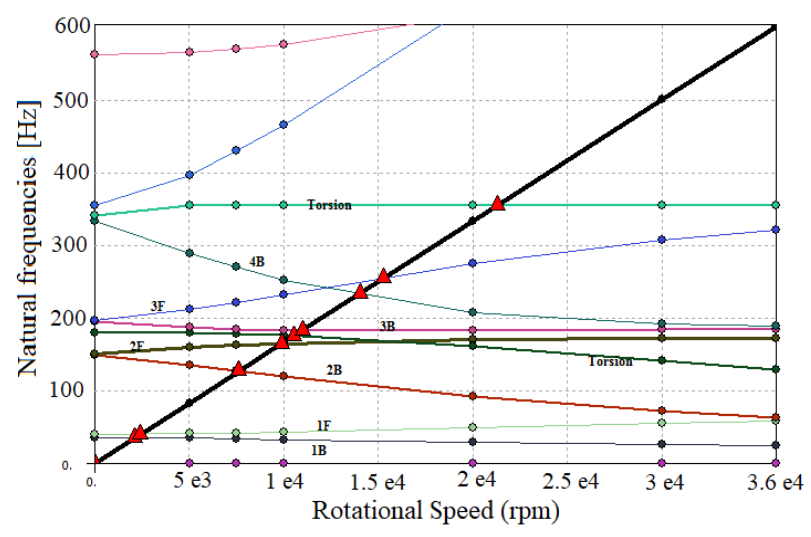

Figure 5. Campbell diagram of the rotor with 2 bearings (3D FE model)

The critical speeds obtained from two models are presented in Table 3. It should be noted that from the beam finite element model, only the bending critical speeds of the rotor are calculated but from 3D finite element model, the torsional and bending critical speeds are calculated.

\begin{tabular}{|c|c|c|c|c|c|}
\hline \multicolumn{1}{|c|}{ TABLE 3. CRITICAL SPEEDS OF THE ROTOR WITH 2 BEARINGS } \\
\begin{tabular}{|c|c|c|c|} 
Critical \\
Speed
\end{tabular} & bending & bending & torsional & bending & torsional \\
\hline Beam & & & & & \\
FE & 2099.97 & 10479 & N/A & 15556 & N/A \\
$(\mathrm{rpm})$ & 2416.2 & 9869.1 & 10503 & 15252 & 21250 \\
\hline $3 \mathrm{D} \mathrm{FE}$ & & & & & \\
$(\mathrm{rpm})$ & & & & & \\
\hline Error & 13.0 & 6.1 & N/A & 1.9 & N/A \\
$(\%)$ & & & & & \\
\hline
\end{tabular}

In order to investigate the dynamic behavior of the rotor more practically and to verify the critical speed obtained from the Campbell diagrams, an imbalance of $1 \mu \mathrm{m}$ is considered at the gravity center of all of the discs which have inner diameter equal to the outer diameter of the shaft where they are located, to simulate the worst unbalancing condition. The imbalance is considered at the gravity center of disks D5, D6, D7, D8 and D10 (Table 1). The operational deflection shapes (ODS) at two bending critical speeds obtained from the Campbell diagrams are shown in Figure 6. 

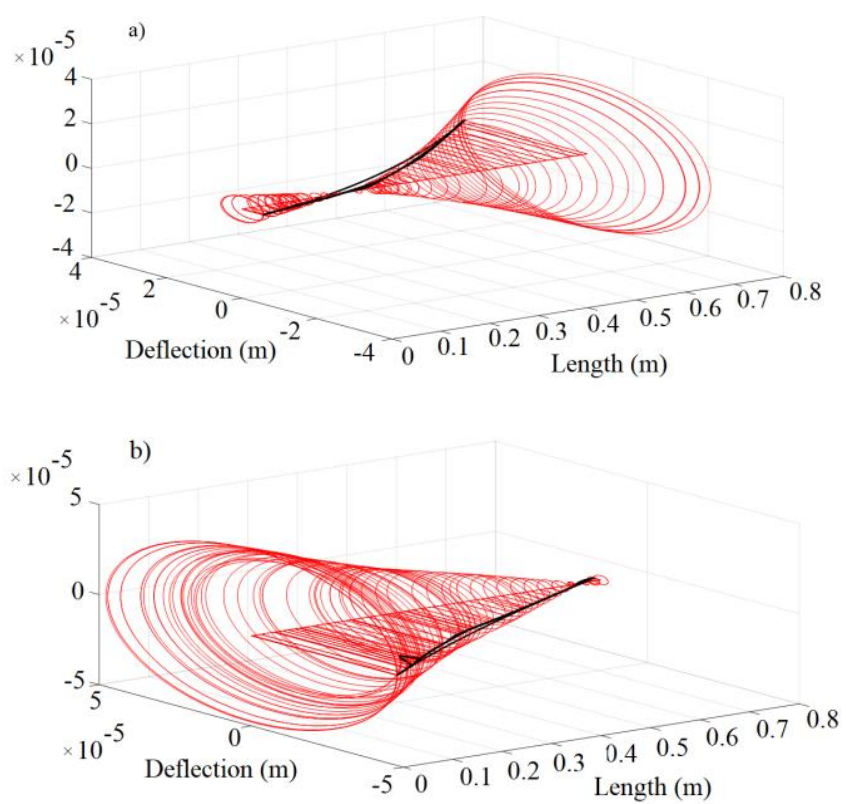

Figure 6. Operational deflection shape of the rotor with 2 bearings at a) first b) second critical speed (Beam model)

Figure 7. shows the unbalance response of the rotor evaluated the location of concentrated masses of disks D5, D6, D7, D8 and D10 at which the imbalance is considered. Nodes 27, 28, $29,30,45$ are the location of concentrated masses of disks D5, D6, D7, D8 and D10, respectively. It can be seen that displacement peaks at the critical speeds points which were previously calculated.

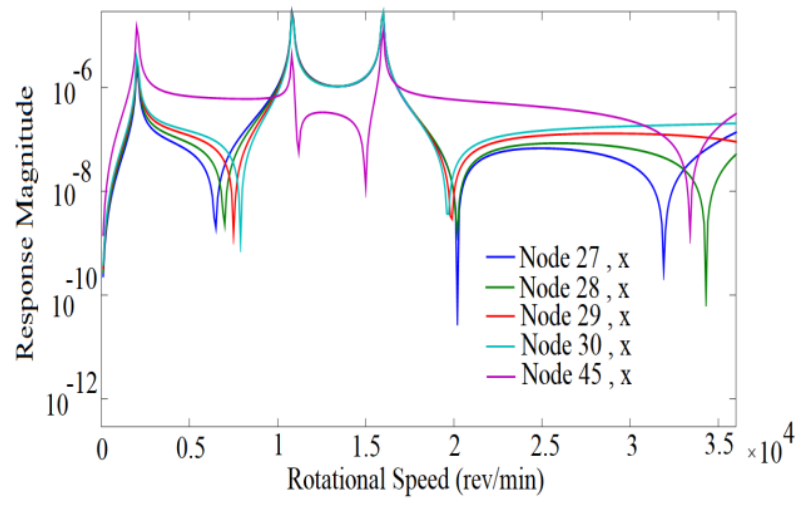

Figure 7. Unbalance response of the rotor with 2 bearings (Beam model)

\section{B. Dynamic Analysis of the Rotor with 4 Bearings}

The Campbell diagram, operational deflection shapes and unbalance response to the worst unbalancing condition is obtained also in this case. The considered speed range is again 0 to $36000 \mathrm{rpm}$. The Campbell diagrams, excluding rigid body modes, obtained from beam FE model and Ansys are shown in the Figure 8 and Figure 9, respectively. The critical speeds obtained from two models are compared with each other in Table 4.

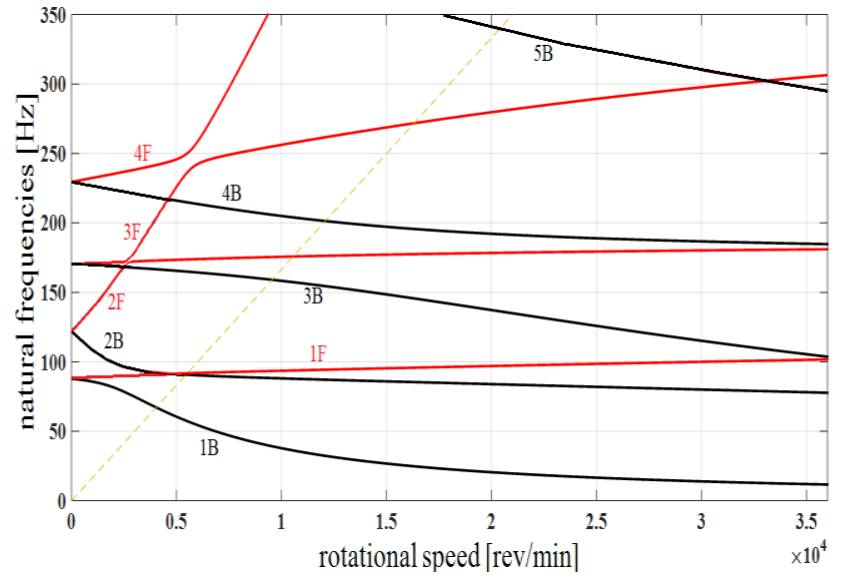

Figure 8. Campbell diagram of the rotor with 4 bearings (Beam FE model)

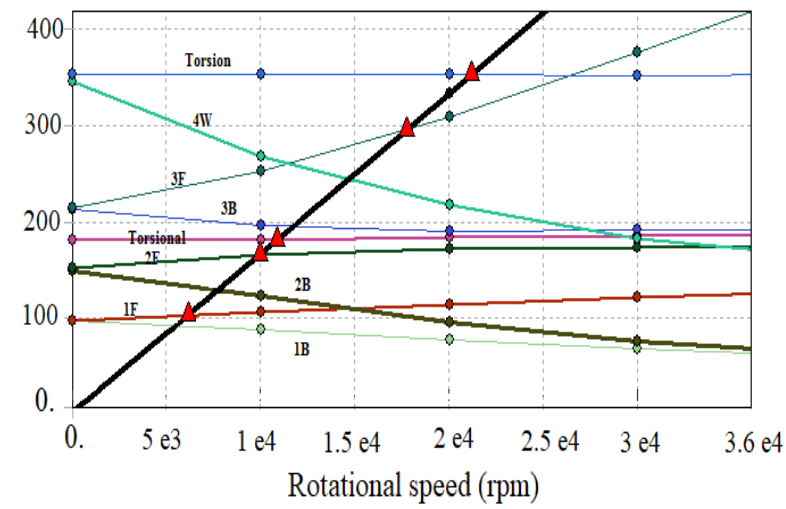

Figure 9. Campbell diagram of the rotor with 4 bearings (3D FE model)

TABLE 4. CRITICAL SPEEDS OF THE ROTOR WITH 4 BEARINGS

\begin{tabular}{|c|c|c|c|c|c|}
\hline $\begin{array}{c}\text { Critical } \\
\text { Speed }\end{array}$ & bending & bending & torsional & bending & torsional \\
\hline $\begin{array}{c}\text { Beam } \\
\text { FE } \\
(\mathrm{rpm})\end{array}$ & 5507.26 & 10549 & N/A & 16308 & N/A \\
\hline $\begin{array}{c}\text { 3D FE } \\
(\mathrm{rpm})\end{array}$ & 5446.9 & 9894.2 & 10868 & 17697 & 21180 \\
\hline $\begin{array}{c}\text { Error } \\
(\%)\end{array}$ & 1.1 & 6.6 & N/A & 7.8 & N/A \\
\hline
\end{tabular}

An imbalance same as which was considered in the previous section is considered also in this case and the operational deflection shapes (ODS) at two bending critical speeds obtained from the Campbell diagrams and the unbalance response are calculated. The operational deflection shapes at two bending critical speeds are shown in Figure 10 
and the unbalance response evaluated at the location of disks D5, D6, D7, D8 and D10 is shown in Figure 11.
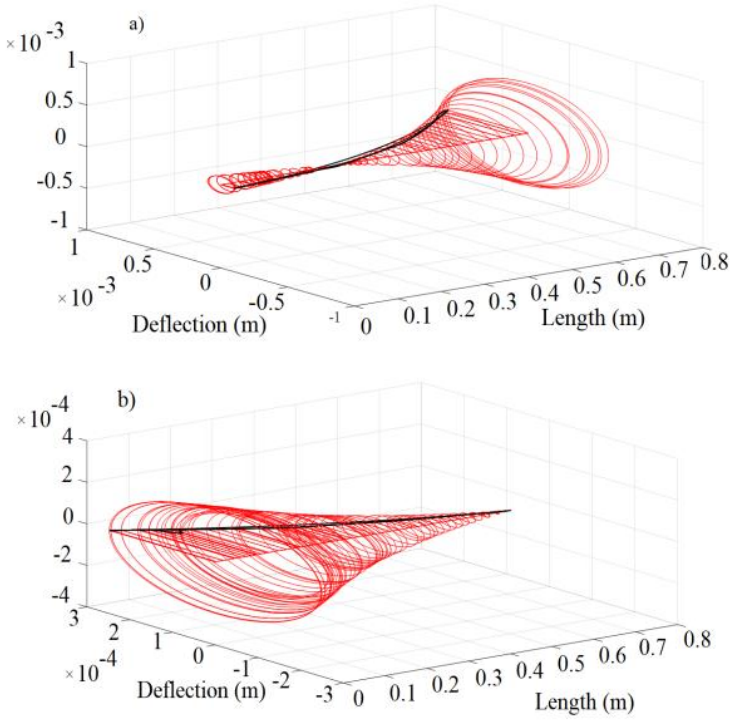

Figure 10. Operational deflection shape of the rotor with 4 bearings at a) first b) second critical speed (Beam model)

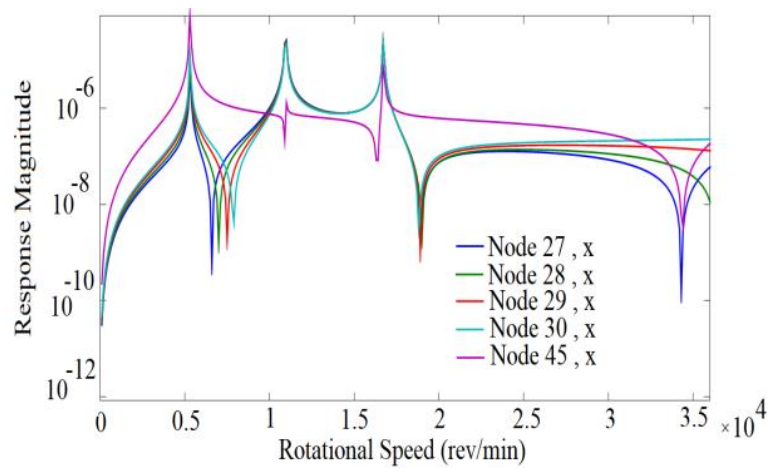

Figure 11. Unbalance response of the rotor with 4 bearings (Beam model)

By comparing the critical speeds of the rotor with 2 and 4 bearings from Tables 3 and 4, it is obvious that the number of the bearings has significant effect on the value of the first critical speed but slight effect on the value of the second and third critical speeds.

Also, by comparing the operational deflection shapes of the rotor with 2 and 4 bearings from Figure 6 and Figure 10, respectively, it is found that the effect of the number of the bearings on the overall deflection of the rotor at the first critical speed is much more than this effect on the overall deflection of the rotor at the second critical speed. In addition, the overall deflection of the rotor with 2 bearings at the critical speeds is much lower than the overall deflection of the rotor with 4 bearings at the critical speeds. It should be noted that in this paper, the effects of the number of the bearings on the dynamics of this rotor is evaluated but the locations of the bearings also can affect the dynamics of the rotor.

\section{CONCLUSIONS}

A finite element model based on Timoshenko beam elements is presented. In this model, various minor and major parts of a gas turbine rotor are modeled using cylindrical and tapered beam elements. A full rotor dynamic analysis is carried out to evaluate the dynamic behavior of the rotor at operational speeds and to avoid vibration problems. Also, a 3D finite element model is constructed, and the lateraltorsional vibration behavior of the rotor is predicted. The comparison of the results shows good agreement between the results obtained from two FE models. The effect of the number of the bearings on the dynamic behavior of the rotor is also studied from the beam finite element model. It is found that the overall deflection of the rotor with 2 bearings (at specific locations) at its first two bending critical speeds is much lower than the overall deflection of the rotor with 4 bearings (at specific locations) at its first two bending critical speed. In addition, it is found that the effect of the number of the bearings on the overall deflection of the rotor at the first critical speed is much more than this effect on the overall deflection of the rotor at the second critical speed.

\section{References}

[1] G. Genta, Dynamics of Rotating Systems, Springer2005.

[2] H. Cao, L. Niu, S. Xi, X. Chen, Mechanical model development of rolling bearing-rotor systems: A review, Mechanical Systems and Signal Processing 102 (2018) 37-58.

[3] B. Shahriari, M.H. Jalali, M. Karamooz Ravari, Vibration analysis of a rotating variable thickness bladed disk for aircraft gas turbine engine using generalized differential quadrature method, Proceedings of the Institution of Mechanical Engineers, Part G: Journal of Aerospace Engineering 231(14) (2017) 2739-2749.

[4] M.H. Jalali, B. Shahriari, Elastic Stress Analysis of Rotating Functionally Graded Annular Disk of Variable Thickness Using Finite Difference Method, Mathematical Problems in Engineering 2018 (2018) 11.

[5] S. Nabavi, L. Zhang, Design and Optimization of Wideband Multimode Piezoelectric MEMS Vibration Energy Harvesters †, 2017.

[6] M. Rafiee, F. Nitzsche, M. Labrosse, Dynamics, vibration and control of rotating composite beams and blades: A critical review, Thin-Walled Structures 119 (2017) 795-819.

[7] M.H. Jalali, B. Shahriari, M. Ghayour, S. Ziaei-Rad, S. Yousefi, Evaluation of Dynamic Behavior of a Rotor-Bearing System in Operating Conditions, World Academy of Science, Engineering and Technology, International Journal of Mechanical, Aerospace, Industrial and Mechatronics Engineering 8 (2014) 1675-1679.

[8] S. Nabavi, L. Zhang, Design and Optimization of Piezoelectric MEMS Vibration Energy Harvesters Based on Genetic Algorithm, IEEE Sensors Journal 17(22) (2017) 7372-7382.

[9] M.H. Jalali, B. Shahriari, O. Zargar, M. Baghani, M. Baniassadi, Free Vibration Analysis of Rotating Functionally Graded Annular Disc of Variable Thickness Using Generalized Differential Quadrature Method, Scientia Iranica (2017) -

[10] B. Parsi, M. Bahrami, A.M. Esfahani, B.S. Sany, Calibration verification of a low-cost method for MEMS accelerometers, Transactions of the Institute of Measurement and Control 36(5) (2014) 579-587.

[11] H.-W. Chiang, C.-N. Hsu, S.-H. Tu, Rotor-Bearing Analysis for Turbomachinery SingleAnd Dual-Rotor Systems, 2004.

[12] S.M. Jeon, H.D. Kwak, S.H. Yoon, J. Kim, Rotordynamic analysis of a high thrust liquid rocket engine fuel (Kerosene) turbopump, Aerospace Science and Technology 26(1) (2013) 169175.

[13] S.-M. Jeon, H.D. Kwak, S. Hwan Yoon, J. Kim, Rotordynamic Analysis of a Turbopump with the Casing Structural Flexibility, 2008.

[14] M.H. Jalali, M. Ghayour, S. Ziaei-Rad, B. Shahriari, Dynamic analysis of a high speed rotor-bearing system, Measurement 53 (2014) 1-9.

[15] M.H. Jalali, M. Ghayour, S. Ziaei-Rad, B. Shahriari, S. Yousefi, Rotordynamic Analysis of a Small Rotor-Bearing System, 4th International Conference on Acoustics and Vibration, Tehran, Iran, 2014.

[16] E. Brusa, G. Zolfini, Dynamics of Multi-Body Rotors: Numerical and Experimental FEM Analysis of the Scientific Earth Experiment Galileo Galilei Ground, Meccanica 37(3) (2002) 239-254.

[17] G. Creci, J. Carlos Menezes, J. Barbosa, J. Aparecido Corra, Rotordynamic Analysis of a 5Kilonewton Thrust Gas Turbine by Considering Bearing Dynamics, 2011.

[18] J.S. Rao, Finite Element Methods for Rotor Dynamics, History of Rotating Machinery Dynamics, Springer Netherlands, Dordrecht, 2011, pp. 269-297. 